\title{
On the role of professional societies in optics and photonics education
}

\section{Marc Nantel, Kathleen Robinson}

Marc Nantel, Kathleen Robinson, "On the role of professional societies in optics and photonics education," Proc. SPIE 8481, Optics Education and Outreach II, 848102 (15 October 2012); doi: 10.1117/12.930323

EDIE Event: SPIE Optical Engineering + Applications, 2012, San Diego, California, United States 


\title{
On the role of professional societies in optics and photonics education
}

\author{
Marc Nantel ${ }^{\mathrm{a}}$, Kathleen Robinson ${ }^{\mathrm{b}}$ \\ ${ }^{a}$ Niagara College, 135 Taylor Road, S.S, \#4, Niagara-on-the-Lake, Ontario, Canada L0S 1J0 \\ ${ }^{\mathrm{b}}$ SPIE, PO Box 10, Bellingham, WA, USA 98227-0010
}

\begin{abstract}
Professional associations can play an important role in the optics and photonics education landscape, enhancing the work done at traditional institutions like colleges and universities. In what way can they best contribute? Should they concentrate on school-children, on working scientists/engineers, or on undergraduate and graduate students? How does one measure the success of their programs? We will present an overview of some programs available, with an eye on their place in the continuum of optics and photonics education and training; we will place a particular emphasis on theneed to measure the impact and outcomes of these learning tools, and will drill down on SPIE's case.
\end{abstract}

Keywords: Professional societies, SPIE, IEEE, AAPT, APS, AAS, photonics education and training, outreach programs, professional development, student chapters, evaluation, assessment

\section{INTRODUCTION}

As time passes, things are meant to get generally better. This is not manifested uniformly across the globe or through all periods -- there have been empires that have fallen and dark ages, along the way -- but in the chronology that took humans from the first homo sapiens to the current modern age, it is fair to say that progress was made, overall. In one particular stream of advancement, communications have greatly changed and improved over the ages. Although there is no consensus on when or how the faculty of speech first appeared [1,2,3,4,5,6], it appears from language diversity and dispersion [7], as well as genetic, archeological and paleontological evidence [8], that it has been around at least for 100,000 years, developing somewhere in sub-Saharan Africa during the Middle Stone Age [9]. Writing developed gradually from picture writing systems in the neolithic $(\sim 7000 \mathrm{BC})$ through to true writing in the early Bronze Age $(\sim 3400-3200$ BC) in Sumeria and Egypt [10,11]. Printing with movable types (Gutenberg, circa 1439) was the next revolutionary step to mass production of books $[12,13]$, and we are now squarely in the digital age.

But hearing an ancient Greek poet -- maybe Homer himself -- reciting his version of the Iliad on the shores of the winedark sea in $850 \mathrm{BC}$ [14] or enjoying the book version on aKindle e-book reader provides essentially the same information, albeit with quite a different experience. The Iliad is still the Iliad, from the point of view of the information imparted. One can imagine the flow of value addition in the communication stream as starting from its basic constituent, "data", which can be organized into "information" which, when some intellect is applied to it, can morph into "knowledge". We are surrounded with data, information and knowledge, most of which is readily accessible to anyone with an internet connection and a device on which to download it. In the 21 st century, knowledge is cheap. It has been more than commoditized; it is essentially free. This is also true for the results of academic research, with the push toward open-access publishing. We contend that where the value resides now, increasingly, is in the next stage in the communication stream, when one reflects on "knowledge" and adds value to it by extracting and communicating the "wisdom" that can be gleaned from it. "Wisdom" -- a term used here loosely and with no pompous intent -- is where the highest value is obtained, and it is not yet something that computers and algorithms can achieve. The powers of analysis and synthesis required to go from "knowledge" to "wisdom" are still something exclusively and exquisitely human.

The case is easily made that the more informed and knowledgeable a population, the better for society. One often hears of people wanting to make "an informed decision" when buying a new car or refrigerator or when about to cast a ballot in an election. Schools are often seen as being set up for "imparting knowledge" on their students. This is a good base from which to start in life, and one would hope that the last stage -- "wisdom" -- is reached eventually by all, in whatever walk of life they have chosen or chanced upon. Professional societies like SPIE are in the business of collecting, publishing and otherwise distributing knowledge -- through conferences, proceedings and journals, for example. The papers that are presented at its conferences and published in its proceedings and journals have already been crunched from "data" to "information" and to "knowledge" (one would hope) by the students and researchers putting them

Optics Education and Outreach II, edited by G. Groot Gregory, Proc. of SPIE Vol. 8481

$848102 \cdot$ ( ) 2012 SPIE · CCC code: 0277-786/12/\$18 · doi: 10.1117/12.930323 
forward. In this paper, the authors explore some of the work conducted by optics and photonics societies to go beyond "knowledge" and into "wisdom" and gives examples of how they accomplish that, for the benefit of the field of optics and photonics, of the people involved, and of society in general.

\section{PROFESSIONAL SOCIETIES EDUCATION MANDATE: CASE OF SPIE}

Professional societies have strong education mandates to serve their constituents and communities. This is especially true in optics and photonics, with varied efforts at SPIE, the Optical Society of America (OSA), the Institute of Electrical and Electronics Engineers (IEEE) and other similar societies. This is one of the principal ways in which they attempt to bring about a more knowledgeable and wiser population. We will examine here in detailhow the SPIE handles its many programs with education as their motivation, and give best-practice examples from other societies in the next section.

\subsection{SPIE's Altruistic Programs portfolio and the evaluation problem}

SPIE devotes much effort and resources on its diverse portfolio of altruistic programs. Those are defined as endeavours that are not meant to bring in revenues, unlike other programs such as the digital library, which contains the SPIE publications and is accessible through a subscription, or the Professional Development Courses, which charge registration fees. The general goal of the altruistic programs is to serve the optics and photonics community by increasing its size, by enhancing its status in the community, by providing development opportunities and by recognizing the accomplishments of its members. Figure 1 shows the current slate of altruistic programs undertaken by SPIE.

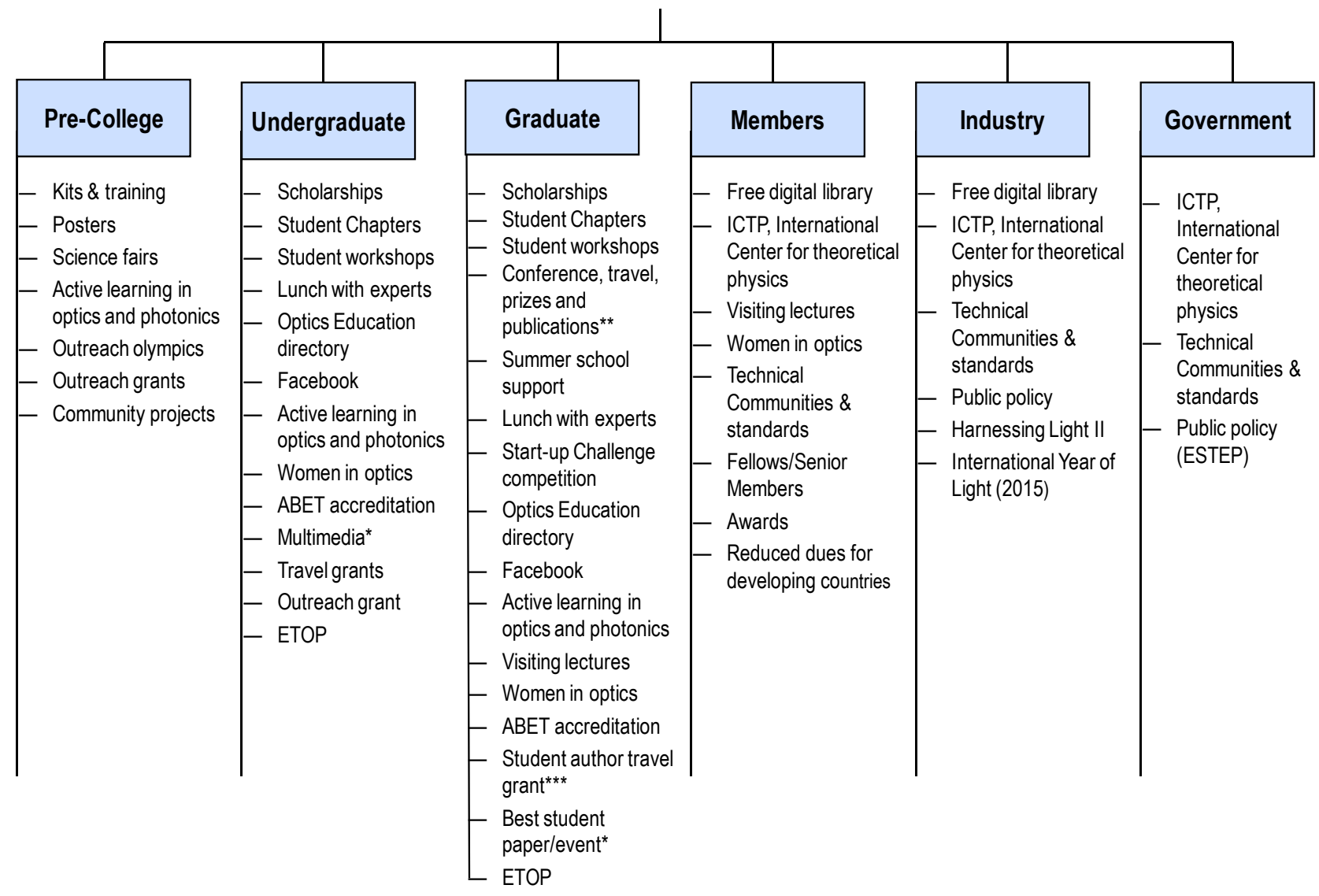

Figure 1. List of the many altruistic programs conducted by SPIE staff, members and volunteers around the world. The Pre-College stream is aimed at K-12 children and their teachers, to increase the visibility of optics and photonics in that community, with the goal of seeing more children and adolescents pursue careers in the field. The Undergraduate stream serves mostly students in science and engineering, with the goal of developing optics learning and their opportunities to enter photonics programs at post-secondary institutions. The Graduate stream aims to serve graduate students in the field. The Members stream covers all members -- academic, industrial, government and others -- and is meant as further benefits of their SPIE membership. The Industry and Government streams are aimed at these two constituencies and their needs. Some programs cross over from one stream to another. 
All this good work requires a sizable budget; Figure 2 and Table 1 show the breakdown of the 2011 expenditures for SPIE's altruistic programs, where the streams introduced in Figure 1 have been regrouped in four broader categories. With \$2.7 million on that effort, SPIE is, on a percentage basis, one of the professional societies with the highest investment in such programs. The bulk of the funds are directed to K-12, undergraduate and graduate students, as well as starting professionals, through the Education Fund $(20 \%$, or $\$ 572,000)$, Students \& Early Career activities $(35 \%$, or $\$ 912,000)$, and Educators \& Teaching Tools $(16 \%$, or $\$ 499,000)$. These programs are for the current crop of future optics and photonics professionals and their development is key to SPIE's mission. Although there is overlap in the purposes of the Education Fund and Educators \& Teaching Tools (mostly on Education and Outreach Grants), and of the Education Fund and the Students \& Early Careers (mostly on Scholarships), the $20 \%$ of the Education Fund is presented separately because it is a Board mandated restricted fund that cannot be used for other purposes.

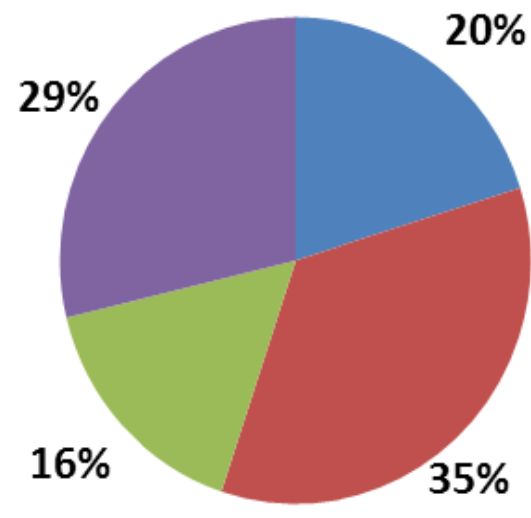

\section{Education Fund}

- Student \& Early Career

Educators \& Teaching Tools

Global \& Advocacy

Figure 2.Proportional breakdown of the \$2.7-million budget for SPIE's 2011 altruistic programs portfolio. For simplicity, the streams introduced in Figure 1 have been regrouped in four broader categories: Education Fund, Students \& Early Career, Educators \& Teaching Tools, and Global \& Advocacy.

\begin{tabular}{|l|c|}
\hline $\begin{array}{l}\text { Education Fund } \\
\text { Scholarships }(\$ 350,000) \text {, Education outreach grants }(\$ 90,000)\end{array}$ & 2011 spend \\
\hline $\begin{array}{l}\text { Student \& Early Career Resources } \\
\text { Student chapters, Author travel grants, activities \& workshops, Lunch with the experts, Start-up Challenge } \\
\text { competitions, Early Career Professional membership, Best student paper prizes, Education directory }\end{array}$ & $\mathbf{\$ 5 7 2 , 0 0 0}$ \\
\hline $\begin{array}{l}\text { Educators \& Teaching Tools } \\
\text { ABET membership, Community programs, Outreach Olympics, O+P Education Conference, ETOP Conference, } \\
\text { Multimedia, Posters, Kits and trainings, Science fairs }\end{array}$ & $\mathbf{\$ 4 9 9 , 0 0 0}$ \\
\hline $\begin{array}{l}\text { Global \& Advocacy Programs } \\
\text { Conference, travel, prize and publishing, Visiting lecturers, Summer school support, Free Digital Library, } \\
\text { Technical communities \& standards, ICTP Winter College and staff, Active Learning in Optics \& Photonics, } \\
\text { Women in Optics, Fellows/Senior Members, Reduced dues for developing countries, Public policy, Harnessing } \\
\begin{array}{l}\text { Light II, International Year of Light } \\
\hline\end{array}\end{array}$ & $\mathbf{\$ 7 8 3 , 8 2 2}$ \\
\hline
\end{tabular}

Table 1.Budgetary breakdown of the \$2.7-million budget for SPIE's 2011 altruistic programs portfolio. The differences between the amounts calculated from the total budget and proportions given in Figure 2 on one hand, and the actual numbers listed in Table 1 on the other hand, are due to a difference in the attribution of internal in-kind resources to the various programs between the two representations. 
SPIE's altruistic programs portfolio highlighted above span several departments and committees of the society. The Scholarship Committee, the Membership Committee, the Engineering, Science \& Technology Policy Committee, the Fellows Committee, the Awards Committee and the Education Committee are the principal ones dealing with these efforts. With so much going on in that portfolio, with its multi-million-dollar budget and distributed accountabilities, three very important considerations are often either forgotten or hard to pin down:

1) How much resource should be allocated to any one of these several individual programs to best serve SPIE's constituents?

2) Which of these programs are successful?

3) How are these programs and their success evaluated in order to guide us to an answer to Questions 1) and 2)?

While all of the programs listed under SPIE's Altruistic Programs portfolio seem, a priori, to be "good ideas" fueled by "good intentions", they often begin as small projects with little resources allocated -- maybe at a society volunteer's suggestion or as a "pet project" -- but can find themselves, several years later, a large part of the offering, with significant budgetary heft. Every now and then, it behooves the society, its staff and volunteers to evaluate the mix of offering and the relative weighting between the different programs and activities. This is the essence of question 1), above. But to answer Question 1), one has to first find the answer to Question 2): are these programs successful, how successful are they and, more fundamentally, in what way are they successful? An ideal answer to Question 2) could be, respectively, "Program X is successful, very successful, and in a way that fowards the goals of the society". Another ideal answer to Question 2 could be "Program Y is not successful, not at all, and even detrimental to the society". If one can honestly answer the question with either one of these extreme answers or even something in between, one can attempt to then answer Question 1) and continuously improve the society's offerings to address the needs of its constituency as best as possible. This is why they would be both "ideal" answers: they would be based on measurements of success.

The crux of the matter, therefore, lies in question 3): are the programs evaluated at all, and if so, in what way? Much too often -- and this is systemic, not just isolated to SPIE offerings --the success of such a program is measured through its level of activity: how many workshops were held and how many people were reached that way, for example. This certainly shows that "someone is doing something", but it doesn't get to the end answer: what were the outcomes of this activity, and how much impact have they had? If 5 workshops were held that reached each 500 people, this may sound impressive, but if all these people got out of it is a day out and a few smiles when the goal of the program was to influence their view of science and direct them to optics and photonicscareer paths, the wrong metrics were collectedand the desired impact was not achieved. The evaluation should report how many of the people touched improved their attitudes toward the sciences and would consider a career in optics. The activity level vs outcomes conundrum in the evaluation of education or altruistic programs is a constant problem and we will get back to it throughout the paper.

\subsection{SPIE's Education Committee Logic Model}

SPIE's Education Committee is constituted of SPIE member volunteers and staff, and it oversees a sizable part of SPIE's altruistic programs portofolio, along with other, revenue-generating programs such as the Professional Development Course program. One of the authors (Nantel) is the outgoing Chair of the Education Committee, ending a 3-year term in the position, and the other (Robinson) is the SPIE Staff Liaison to the Committee. In order to tackle the questions about how programs are evaluated, we switch our attention from the overall altruistic programs portfolio to that of the Education Committee, with which there is much overlap.

In order to make a start on answering questions 1) through 3) above for its offerings, the Education Committee decided, in 2009, to get a good handle on what all the programs were that it was offering and how they related to SPIE's general (and its Education Services department's specific) goals. The framework that was used for this exercise is that of the Logic Model. In a properly constructed logic model, one can follow the flow downwards from the uppermost strategic level (vision/mission) to the most tactical levels (specific activities and resources) with clear relations between each level. This facilitates an understanding of why and how the activities undertaken relate to and advance the goals of the corporation (or division, or departement, or project...). When an activity appears not to fit in the logic model, it should either not be undertaken, or the logic model -- right up from the vision/mission, potentially -- needs to be adjusted to take the new activity into account and remain self-consistent. At the very least, the use of a logic model crystallizes the mind around what one is really trying to achieve, whether one is going about it the right way, and whether all activities undertaken advance the intended purposes of the overall enterprise. It forces one to think strategically when making decisions. Figure 3, on the next two pages, shows SPIE's Education Services logic model. 


\section{SPIE EDUCATION SERVICES - STRATEGIC LOGIC MODEL}

SPIE Mission/Vision: SPIE partners with researchers, educators, and industry to advance light-based research and technologies for the betterment of the human condition.

Education Services Mission: To provide continuing education and professional development products that meet the educational needs of SPIE's engineering, scientific, and business constituencies, to support and promote science, technology, engineering and math education worldwide, and to increase public awareness of the field and its applications.

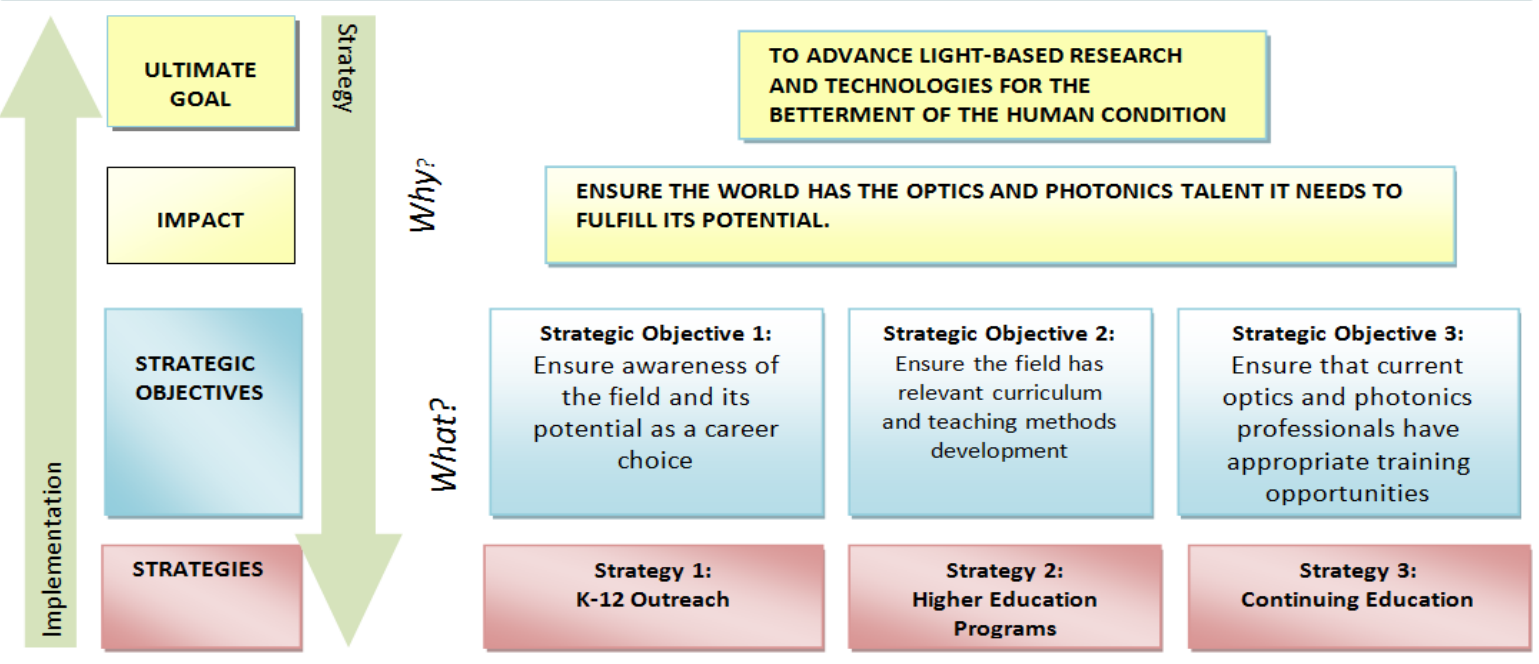

Figure 3a."Top" portion of the SPIE Education Services' logic Model, from Mission/Vision to Strategies.

\section{Strategy 1: K-12 Outreach}

\section{Situation Statement:}

The future of any discipline depends on its ability to attract young people into the field. Providing outreach opportunities and resources to the community is important to maintaining a pipeline of students that will provide future engineers, scientists and technicians.

In addition, public funding is critical to the advancement of any technology. Community outreach increases public awareness of optics and photonics and the importance it has to everyday life. This awareness helps people to realize the benefits of the technology and will encourage the public funding necessary for research and the advancement of the field.

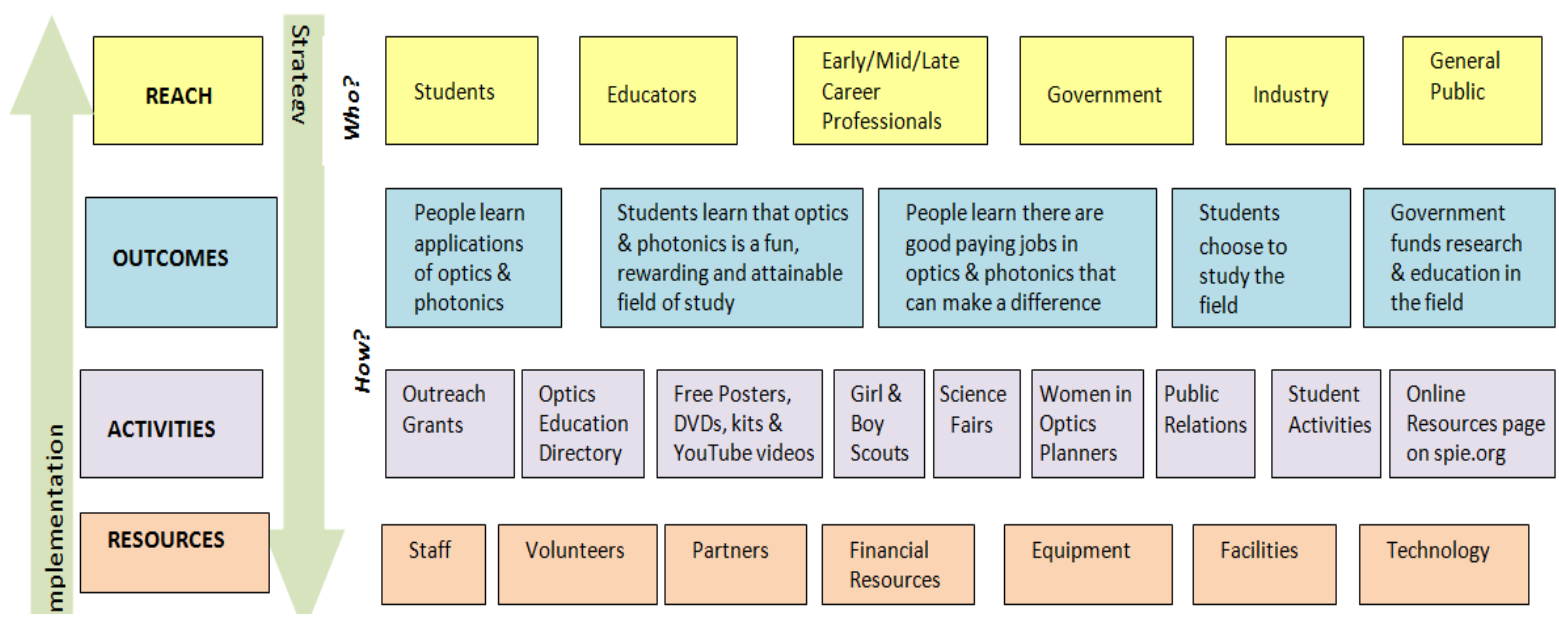

Figure 3a."Bottom" portion of the SPIE Education Services' logic Model, for Strategy 1, K-12 Outreach. 


\section{Situation Statement:}

Students need access to university programs that provide the science and engineering education critical to building a foundation in the field. These programs also need criteria specific to the field in order to ensure graduates have the background they need to succeed in the field. It is important that institutions of higher education have both relevant curriculum and that the curriculum is presented in the most effective manner, utilizing proven education methodology. Adherence to these standards is ensured through the accreditation process.

In addition, science higher education is critical to improving the economy in developing nations. Developing nations need access to quality curricula and teaching methods relevant to the field.

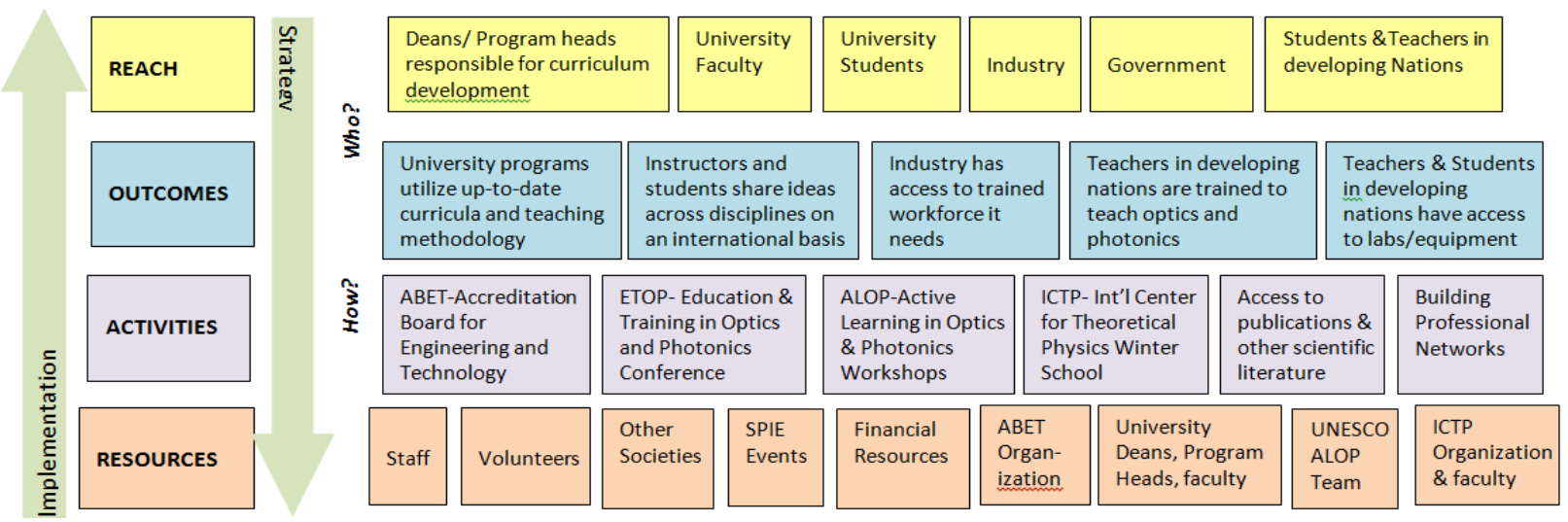

Figure 3c."Bottom" portion of the SPIE Education Services' logic Model, for Strategy 2, Higher Education Programs.

\section{Strategy 3: Continuing Education}

Situation Statement: Optics and photonics is a rapidly growing field with many applications in today's world. It is an enabling technology and, as such, spans a cross-disciplinary field. Many engineers and scientists who have been trained in other disciplines still need education and training in optics and photonics. In addition, the technology and its applications are advancing quickly and individuals working in the field need constant updates. Continuing education in optics and photonics is critical to building skills and knowledge necessary for creating new applications and advancements in the field.

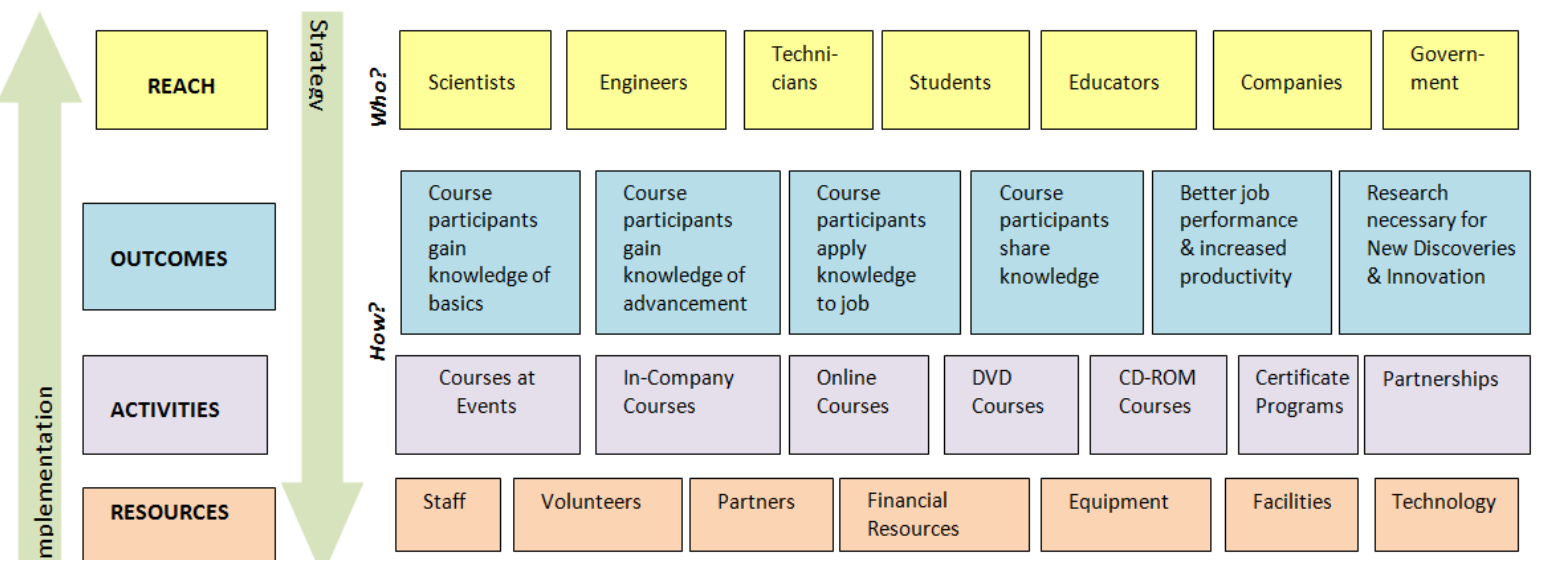

Figure 3d."Bottom" portion of the SPIE Education Services' logic Model, for Strategy 3, Continuing Education. 
All the programs currently offered by the SPIE's Education Services, and that are the purview of the Education Committee, fit neatly into the logic model. Should a suggestion for a new program surface, it would be evaluated with the logic model in mind to see if it can find a place in it. If it doesnot, it would either be rejected, directed to another committee or, if it proves compelling enough to justify a change in the Education Services' Mission/Vision statement, it would be integrated into a revised logic model. The first step in properly handling program mix and resourcing is in place. Next is the examination of how, if at all, the programs are evaluated.

\subsection{Examples of evaluation for SPIE's Education Programs}

The logic model certainly highlights that there is a lot of activity on the education front at SPIE, but how does one know if the mission and vision of the Education Services are being achieved? DoesSPIE measure the outcomes and impact of its various education offerings? The best answer, at present, appears to be "sometimes"; it depends on the individual program and it seems to follow that the bigger the resource investment, the more likely it is to be evaluated. Furthermore, the way those programs are evaluated varies from program to program. When one considers the investment in the K-12 Outreach programs, for example, one cannot help but ask: "Should we be doing more systematic evaluation of their success? Shouldn't we be tracking our Return on Investment? What are those programs that are really helping us to achieve our goals? And what are the ones that are not so productive?" Program assessment is critical in resource allocation. Below are examples of how SPIE evaluates some its programs:

\subsubsection{Professional Development Course Program}

Strategy 3 in the logic model is Continuing Education, and a large part of this thrust are the Professional Development Courses. These courses are offered at SPIE's conferences, in-company and in various multi-media formats; they are meant to supplement the learning that graduate students receive in their degree programs and to provide professional development for already employed professionals in the field. Here is an example where the evaluation process is extensive and comprehensive, giving a good idea of the programs' success. The course materials, curricula and instructors have been systematically evaluated by SPIE for more than 27 years. There is an evaluation form in every set of course notes, on which attendees are asked to rate both the course and the instructor on aspects of the course such as subject-matter expertise, course organization, presentation and whether or not the content was applicable to the attendees' work. These aspects are rated on a scale of 1 to 5 , and the courses that do not consistentlyscore an average of 4 or above are not repeated.There is also space provided on the evaluation forms for anecdotal comments. For financial reasons, SPIE also looks at the course attendance numbers; if a course consistently has fewer than 10 attendees, it is not likely to get renewed because it is likely not financially viable. The best indication that the outcomes and impact of this program are positive is the popularity of the courses in general and return business from individual attendees.

In addition, SPIE's education program's policies and processes are in compliance with the ANSI/IACET Standard for Continuing Education. IACET, the International Association for Continuing Education and Training, established with ANSI, the American National Standards Institute,thiswidely acceptedstandard for continuing education. Organizations with Authorized Provider status in IACETare evaluated every 6 years and,to maintainAuthorized Provider status, must comply with the 10 categories of the standard, including learning environment, event planning, learning outcomes, instructional personnel, content and methods, assessment of outcomes, learner records, and program evaluation.SPIE went through itsreview process last year and retained its Authorized Provider status. This isanother method by which the quality of SPIE's Professional Development Courses programs are evaluated.

\subsubsection{Scholarships}

Strategy 2 in the logic model touches on Higher Education Programs, which include Scholarships. SPIE offers Educational Scholarships for all students from high school (pre-university/secondary) through PhD. SPIE also offers Travel Scholarships to SPIE symposia for undergraduates and graduate students who are not in doctoral programs. The goal of the Scholarship Program is to support students interested in or already studyingoptics and photonics disciplines. Through 2011, SPIE has distributed over \$3.3 million in scholarships to 1,905 students across 86 countries; in 2011 alone, SPIE awarded $\$ 350,000$ in individual scholarships ranging from $\$ 2,000$ to $\$ 11,000$ in value. While it is difficult to question the intrinsic value of such a scholarship program, to date SPIEhas not systematically measured the success of its scholarship program. There have beenintermittent reports in the past, tracking various aspects of the scholarship recipients, including continued membership in the Society, attendance at SPIE events, and the authoring of papers. There are many individual stories and anecdotal evidence that the program can change lives and career paths, but it may be time to considerdevisinga systematic process to track and analyze this information to better assess the success of the program. 


\subsubsection{Student Chapters}

Another part of Strategy 2 is the support to SPIE Student Chapters. SPIE-affiliated student groups are studying optics and photonics at universities and colleges around the world.There are currently 194 SPIE Student Chapters, with more than 4,500 members in 40 countries; a map of the chapter distribution is shown in Figure 4 [15]. Aspects that are monitored include how many members a particular chapter has, the chapter's outreach activities, and whether or not the members of the chapter are getting out into the community and increasing awareness of optics and photonics. This is tracked this through an annual report requirement. SPIE also looks at a chapter's use of the many benefits that are offered to them: activity grants, visiting lecturers, leadership training. SPIE is looking at an "Alumni Program" that would track how many of the Student Chapter members actually become members of the Society upon graduation. Through these various ways of assessing the student chapters, it appears that SPIE has a reasonably comprehensive system for monitoring not only the success of individual chapters, but also the Student Chapter program as a whole.

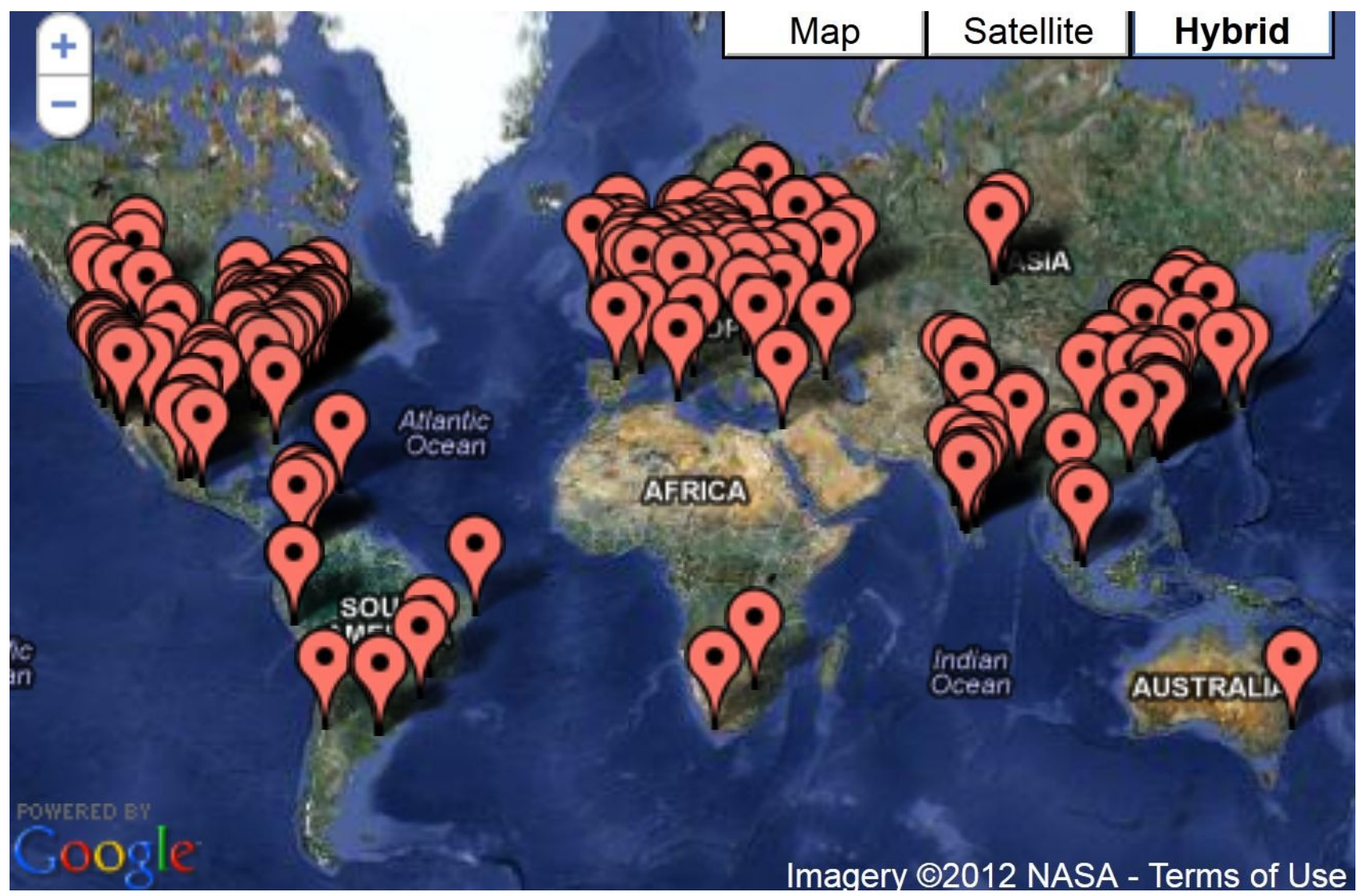

Figure 4.Map of the distribution of the SPIE Student Chapters worldwide.

\subsubsection{Outreach Grants}

Strategy 1 in the logic model deals with K-12 Outreach. The goals of this program are essentially to prime the pump for the flow of young talent into optics and photonics disciplines by exposing them to optics at a young age, and to raise the general awareness of the field in the community. The outreach grants are awarded twice per year, with an eye on the potential outcomes, as promised in the applicants' proposals. The awards are small -- in the $\$ 1,000$ to $\$ 5,000$ range -and currently total $\$ 90,000$ per year. The applications go through a rigorous review process in the Outreach Grant subcommittee (which reports to the Education Committee) and the use of awarded funds is tracked through final reports from the grant recipients. At this point, though, the data is not systematically compiled and the program has not been evaluated for overall success; this may be a direction SPIEwill want to take in the future.Certainly,one place to start is with the goals of the outreach grants: impacting students and increasing optics awareness. The SPIE Education Committeeis currently looking at devisingmetrics around the goals to determine the success of the program. 


\section{BEST PRACTICES FROM OTHER SOCIETIES AND ORGANIZATIONS}

The previous section took a look at some of the ways in whichSPIE attempts to bring more "knowledge" and "wisdom" to the world of optics and photonics through its altruistic and education programs. The point was made that, given the resources deployed by the Society toward that goal, a good understanding of the worth and success of each program should be paramount, especially when it comes to deciding on the mix of programs and their funding. As seen above, the quality of the assessment for the SPIE programs highlighted is at present uneven, at best. The under-evaluation of such activities is by no means limited to SPIE and is fact endemic of the altruistic and education field. There is a strong desire at SPIE to give itself better tools for evaluation. A realization that evaluating quantitatively the impact and outcomes of such programs is a complex task and not easily undertaken calls for an exploration of best practices in that regard. In this section, we talk about a few of the best practices the authors have found with other professional societies, and with practitioners of STEM outreach.

\subsection{IEEE's TISP -- Teacher in-Service Program}

The IEEE runs a program called TISP, which stands for Teacher In-Service Program [16]. The program's goals are to empower IEEE section volunteers to collaborate with their local pre-university community;promote applied inquirybased learning;enhance the level of technical literacy of pre-university educators;encourage pre-university students to pursue technical careers, including engineering; and increase the general level of technical literacy of pre-university students throughout their educational careers.Very few primary and middle-school teachers have science and engineering in their background, and it can be sometimes intimidating for them to teach scientific and engineering concepts in the few parts of the curriculum where it appears. One way to prepare these teachers and dispel some of their discomfort is to provide them with training in these subjects. This "train the teacher" modality provides arelativelyefficient way of expanding the reach of science, technology, engineering and math (STEM) outreach efforts: one volunteer conducting a workshop on engineering and engineering design to 25 teachers empowers those 25 teachers to teach 25 students and the multiplicative effectbrings to 625 individuals the efforts of 1 volunteer, in any given year (a teacher whose career spans 30 years could actually see upwards of 30 times 25 students). In addition to reaching impressive numbersthrough the TISP program, IEEE also systematically evaluates the program and its effectiveness. The process is transparent and it is easy to find a copy of the evaluation form online to see what questions are asked showing what aspects of the program are evaluated.Those include, on a 4-point scale, questions such as "This program has added to my technical knowledge base", "I will use the concepts presented in my classroom instruction in the next 6 months/semester", and "The hands-on activities will increase my student's levelof technological literacy". These questions drill down to the outcomes desired and attempt to measure the actual impact of the program. Equally laudable is the fact that IEEEcompiles and publishesits results online to allow their members to see what kind of response the program is getting from the community they are trying to serve.

\subsection{AAPT/APS/AAS New Faculty Workshops}

The American Association of Physics Teachers (AAPT), in cooperation with the American Physical Society (APS) and the American Astronomical Society (AAS), offers a program to help new faculty at 4-year institutions become better educators. This program assembles leading figures in physics education to teach simple techniques that make these new faculty better, more effective teachers. It is encouraging to see that the organizers recognize that an individual being a subject-matter expert doesnot necessarily mean that s/he knows how to teach it to others.Department chairs are asked to recommend faculty to attend, and there has been such a demand that there are now waiting lists for the workshops, whichis a good indication that the program is meeting a real need.The National Science Foundation supports and funds the New Faculty Workshops. On the evaluation side, the organizers have hired an external evaluator to assess the program on a regular basis. There is an excellent report published in the American Journal of Physicsabout the program itself that also provides a good example of the evaluation process for these kinds of programs and confirms the wisdom of hiring an outside evaluator [17].

\subsection{Scientists in Schools}

Scientists in School (SiS) is a dynamic Canadian charity dedicated to helping children and youth reach their full potential; one of the authors (Nantel) is a volunteer Director of the corporation. Founded in 1989 in Ajax, east of Toronto, Ontario, Canada, SiS enables Kindergarten to Grade 8 students to become 'scientists in their school', catalyzing long-lasting interest in science, technology, math, environmental stewardship and engineering. By fostering learning through highly investigative classroom or community workshops, SiS helps make even the most reluctant science learner enthusiastic. SiS provides opportunities for young learners to interact with ecologists, physicists, engineers and more 
over the course of their elementary education, opening their minds to future careers in science-related fields and fostering innovation. SiS broadens its impact further through participation in countless community events and also acts as a voice for science promotion. Most of all, they aim to make science fun. Across 240 Ontario and Alberta communities, SiS currently touches close to 600,000 students and 75,000 teachers and parent volunteers during their classroom workshops and thousands more in community settings, and reached its 5-millionth child "scientist" in January 2012 [18].

Scientist in School conducts thorough evaluations of its program and its outcomes through a variety of surveys(including pre- and post-workshop questionnaires with the children), teacher and parent focus groups, paired classrooms (with and without SiS programs), repeat business and overall program growth (word-of-mouth positive recommendations). In a 2006 report on their activities, for example, SiS found that, as a result of their workshops, $75 \%$ of students were more interested in science, $99 \%$ of teachers reported their students' learning was enriched, and $90 \%$ indicated their own confidence in teaching science and technology was enhanced [19]. SiS recognizes the challenges surrounding the quantitative assessment of programs aimed at turning young children toward science. To do a full, multi-year longitudinal study following kindergarten children through to their university choices is prohibitive, but they are currently considering ways to tap into high-school reunions in the districts where their programs have had good penetration for several years to reconnect with young adults who have participated in their early workshops andmeasuretheir impact on career choices. These long-term surveys would provide the best data yet as to the impact of programs such as Scientists in School's.

\section{CONCLUSION}

There is much that professional societies like SPIE can do to foster a more knowledgeable and "wiser" population. We have outlined several ways in which they do. While data/information/knowledge is relatively easy to come by, the types of interactions and experiences supported by programs such as Professional Development Courses, Student Chapters, Outreach Grants, Teachers-in-Service, New Faculty Workshops, and Scientists in School, go further into making our population smarter, better connected, empowered. It is a key mission of many of these professional societies, and the work done by their staff and volunteer is critical to the future of our society in general.

One aspect of all this activity that is identified as generally needing improvement are the assessment processes to determine the success of these types of programs. To go beyond the simple "activity" measures into the more crucial "outcomes" and "impact" measures is something that all these programs should aspire to do. If anything, it would provide a way to quantify progress toward the goals of the programs, and make it easier to convince funders and supporters to continue or increase their involvement. When resources are scarce and difficult decisions need to be made on where to invest altruistic or education efforts, the programs that can measurably demonstrate their efficacy and impact will -- or should -- be those receiving the lion's share of funding. We gave several examples of best practices, in the hope that more will be done along those lines.

\section{ACKNOWLEDGEMENTS}

The authors would like to thank Theodore Hodapp of the APS and Robert Hilbornof(AAPT) and David Sokoloff of AAPT and the University of Oregon for providing information on the New Faculty Workshop; KrisindaPlenkovich of SPIE for the charts and graphs related to SPIE's altruistic spending; June Thompsonof SPIE for information on SPIE Student Chapters; and Pascale Barnett of SPIE for information on the Outreach Grants Program. We would also like to thank Col. Barry Shoop of West Point for introducing us to the TISP program and acknowledge the IEEE website for providing a wonderful source of information about it. Finally, the authors are grateful for the time and information that Cindy Adams from Scientists in School shared with them for this paper.

\section{REFERENCES}

[1] Chomsky, N.,"Language and Mind: Current thoughts on ancient problems. Part I \& Part II", in Lyle Jenkins (ed.), Variation and Universals in Biolinguistics. Amsterdam: Elsevier, pp. 379-405(2004).

[2] Chomsky, N., "Three factors in language design". Linguistic Inquiry36(1): 1-22 (2005). 
[3] Pinker, S. and Bloom,P.,"Natural language and natural selection",Behavioral and Brain Sciences 13: 707-84 (1990).

[4] Pinker, S.,The Language Instinct. London: Penguin (1994).

[5] Ulbaek, I.,"The origin of language and cognition", in J. R. Hurford, M. Studdert-Kennedy and C. D. Knight (eds), Approaches to the evolution of language: social and cognitive bases. Cambridge: Cambridge University Press, pp. 30-43 (1998).

[6] Tomasello, M.,"The cultural roots of language", in Velichkovsky, B. M. and D. M. Rumbaugh (eds), Communicating Meaning. The evolution and development of language. Mahwah, NJ: Erlbaum, pp. 275-307 (1996).

[7] Nichols, J., "The origin and dispersal of languages: Linguistic evidence", in Nina Jablonski and Leslie C. Aiello, eds., The Origin and Diversification of Language, pp. 127-70. (Memoirs of the California Academy of Sciences, 24.) San Francisco: California Academy of Sciences (1998).

[8] Perreault, C. and Mathew, S., "Dating the origin of language using phonemic diversity",PLoS ONE 7(4): e35289. Doi:10.1371/journal.pone.0035289 (2012).

[9] Botha, R. and Knight, C., (eds) The Cradle of Language. Oxford: Oxford University Press (2009).

[10] Robinson, A., "The Origins of Writing" in David Crowley and Paul Heyer (eds) Communication in History: Technology, Culture, Society (Allyn and Bacon, 2003).

[11] Kramer, S.N., The Origin and Development of the Cuneiform System of Writing", Thirty Nine Firsts In Recorded History pp 381-383.

[12] McLuhan, M.,The Gutenberg Galaxy: The Making of Typographic Man (1st ed.). University of Toronto Press. ISBN 978-0-8020-6041-9 (1962).

[13] Eisenstein, E.L.,The Printing Revolution in Early Modern Europe (2nd, rev. ed.). Cambridge University Press. ISBN 0-521-60774-4 (2005).

[14] Herodotus.The History, translated by David Grene. University of Chicago Press. ISBN 0-226-32770-1 (1987).

[15] http://spie.org/x1727.xml, accessed on 14 August 2012.

[16] http://www.ieee.org/education_careers/education/preuniversity/tispt/index.html, accessed on 14 August 2012.

[17] Henderson, C., "Promoting instructional change in new faculty: An evaluation of the physics andastronomy new faculty workshop", Am. J. Phys., 76, No. 2 (2008).

[18] http://www.scientistsinschool.ca/, accessed on 16 August 2012.

[19] Cindy Adams, Executive Director, Scientists in School, private communication (2012). 